We acknowledge the work of the haematology laboratory, Fazakerley Hospital, without which this study would not have been possible.

\footnotetext{
References

${ }^{1}$ Mollison PL. Blood transfusion in clinical medicine. Oxford: Blackwell Scientific Publications, 1956.

2 Peevy KJ, Wiseman HJ. ABO haemolytic disease of the newborn: evaluation of management and identification of racial and antigenic factors. Pediatrics 1978;61:475-8.
}

${ }^{3}$ Kapean E, Herz F, Scheye E. ABO hemolytic disease of the newborn without hyperbiliruminemia. Am J Hematol 1976;1:279-82.

${ }^{4}$ Miller DF, Petrie SJ. Fatal erythroblastosis secondary to ABO incompatibility. Obstet Gynecol 1962;22:773.

${ }^{5}$ Grundbacker FJ. The etiology of ABO hemolytic disease of the newborn. Transfusion 1980;20:563-8.

Correspondence to $\mathrm{Dr} M \mathrm{~W}$ Quinn, Institute of Child Health, 30 Guilford Street, London WC1N 1EH.

Accepted 12 May 1988

\title{
Ataxic cerebral palsy and genetic predisposition
}

\author{
G MILLER
}

\author{
Neuromuscular Research Institute, Nedlands, Western Australia
}

SUMmaRY It was calculated that in the 962 family members of 36 patients with ataxic cerebral palsy there were $75(8 \%)$ with a history of neurodevelopmental disorder and $31(3 \%)$ with a major congenital malformation. This was not significantly greater than expected, and does not support the hypothesis of a genetic non-Mendelian role in the aetiology of ataxic cerebral palsy.

It has been suggested that a genetic non-Mendelian influence may play a part in a multifactorial aetiology in cerebral palsy. This gives rise to a constitutional vulnerability to several risk factors and a predisposition to neural tissue damage, and is expressed as an increase in neurodevelopmental disability and major congenital malformation in the near relatives. ${ }^{12}$ In ataxic cerebral palsy, the least common of the syndromes of cerebral palsy, the infants are usually of normal birth weight with a prenatal origin of the condition. ${ }^{3}$ The family histories of a population with this disorder were therefore examined for the frequency of neurodevelopmental disability and major congenital malformation in order to assess the role of a genetic influence in aetiology.

\section{Subjects and methods}

Cerebral palsy is defined as a group of disorders of movement and posture due to a non-progressive defect or lesion of the developing brain. ${ }^{4}$ When this disorder is an ataxia, which is not primarily due to weakness, spasticity, dystonia, or choreoathetosis, it is termed ataxic cerebral palsy.

Thirty six cases of ataxic cerebral palsy were ascertained from the West Australian cerebral palsy register and from the records of the Spastics Welfare Association of Western Australia. Each case was individually examined to ensure they fulfilled the criteria for diagnosis. All were older than 5 years of age and had histories consistent with a nonprogressive disorder. The number of cases of ataxic cerebral palsy ascertained represented $72 \%$ of the metropolitan population (details to be published elsewhere).

A history of neurodevelopmental disability or major congenital malformation in the parents, aunts and uncles, first cousins, siblings, and children of siblings, was recorded. The categories of neurodevelopmental disability used are listed in the table. Details of these were checked against the medical records of several institutions and by correspondence with the relevant personnel who were concerned.

\section{Results}

Out of a total of 962 people on whom information was sought, $75(8 \%)$ had neurodevelopmental dis-

\section{Table Categories of neurodevelopmental disability}

Intellectual handicap

Cerebral palsy

Language delay or disorder ascertained by specialist consultation Epilepsy of unknown origin

Congenital hearing loss

Severe visual handicap

Congenital strabismus

Special educational requirements-remedial teaching, special class or school (where the reason was not considered to be primarily socioemotional) 
abilities and 31 (3\%) had major congenital malformations. In a few instances (nine) the history of a relative was uncertain or could not be verified, and they were removed from the calculations.

There were two sisters with a similar nonprogressive ataxic disorder whose histories and computed tomograms could have been consistent with Joubert's syndrome, and one boy whose mother had a similar condition.

\section{Discussion}

The prevalence of neurodevelopmental disability in a general population similar to the one reported here and using similar criteria, has been reported to be $12-16 \% .5$ An increased frequency of neurodevelopmental disability in the direct families and near relatives of those with ataxic cerebral palsy could thus not be shown. The figure of $8 \%$ is somewhat low, and this may have been due to underascertainment as, although a thorough history was taken and parents were asked to contact their relatives, a disability may not have been admitted. However, about 100 cases would have to be missed to achieve an $18 \%$ incidence of neurodevelopmental disability and it is most unlikely that those numbers were missed. It would have been more satisfactory if the frequency of neurodevelopmental disability in the local population had been known.

The figures for 1980-3 for the percentage of Western Australian births with a major congenital malformation ranges from $3 \cdot 2 \%$ to $4 \cdot 2 \%$ (Western Australian Congenital Malformations Register Annual Report, 1984), a similar figure to that found in the current study.

Ingram, ${ }^{6}$ in his study of ataxic cerebral palsy, reported a high proportion of near relatives with different types of neurological disorder, and Mon- real in a clinic population study of cerebral palsied children stated that there was an unusual number of relatives with cerebral palsy, mental retardation, and seizures. ${ }^{2}$ The methods used in those two studies differ, however, from those used in this report, and the results are not really comparable.

This study of a large proportion of a metropolitan population of patients with ataxic cerebral palsy does not support a genetic non-Mendelian influence in the aetiology of this heterogeneous disorder.

I am indebted to Dr Fiona Stanley and Linda Watson for access to the West Australian cerebral palsy register, the Spastics Welfare Association of Western Australia, and to Carolyn Ebell for preparation of the manuscript.

\section{References}

${ }^{1}$ Stanley FJ. Prenatal risk factors in the study of the cerebral palsies. In: Stanley FJ, Alberman E, eds. The epidemiology of the cerebral palsies. Clinics in developmental medicine No 87. Spastics International Medical Publications. Oxford: Blackwell Scientific Publications Ltd, 1984: 87-97.

2 Monreal FJ. Considerations of genetic factors in cerebral palsy. Dev Med Child Neurol 1985;27:325-30.

3 Hagberg B, Hagberg G, Olow I. The changing panorama of cerebral palsy in Sweden. 1954-1970. II. Analysis of various syndromes. Acta Paediatr Scand 1975;64:193-200.

4 Bax M. Terminology and classification of cerebral palsy. Dev Med Child Neurol 1964;6:295-7.

5 Drillien C, Drummond M. Developmental screening and the child with special needs. A population study of 5000 children. Clinics in developmental medicine No 86. Spastics International Medical Publications. London: William Heinemann Medical Books Ltd, 1983:55-89.

${ }^{6}$ Ingram TTS. Congenital ataxic syndromes in cerebral palsy. Acta Paediatr Scand 1962;51:209-21.

Correspondence and address for reprints to Dr G Miller, Department of Pediatrics, Division of Neurology, Milton S Hershey Medical Center, Pennsylvania State University, PO Box 850, Hershey, PA 17033, USA.

Accepted 3 February 1988

\title{
Have school entry medicals had their day?
}

\author{
F D KENNEDY
}

Carnmoney Health Centre, Newtownabbey, Northern Ireland

SUMMARY Examination of the school health records of 1033 primary school entrants showed that there was a high level of preschool surveillance by health visitors and that most problems recorded at school entry medical examinations were already known to another professional.
It is policy in Northern Ireland that all children commencing primary school are given a school entry medical examination. There are widely differing views held about the value of these routine examinations. Some believe they are of little value ${ }^{1}$ while others consider them to be of special importance. ${ }^{2}$ The aims of this study were firstly to determine the number of children with records of preschool 